\title{
The Influence of Japanese Anime Language to Chinese Network Buzzwords
}

\author{
Jin Chang Cai
}

Teacher's College, Beihua University, Jilin, China

\begin{abstract}
In this paper, the influence of Japanese anime language to Chinese network buzzwords was studied, and the maturity and rigor were quoted. The Japanese anime language refined, creative can be so popular in the factors of psychologies also was analyzed. According to these studies, some suggestions were put forward that how to standardize the network buzzwords and how to raise its taste.
\end{abstract}

\section{General instruction}

Extensive use of modern Chinese vocabulary of Japanese origin, mainly the late Qing Dynasty in the early Ming Dynasty was introduced into China from Japan. When Japanese considerable number of translations, the introduction of advanced technology modern Western thought and science and technology, culture based on Chinese characters, foreign words through their transformation, innovation and then back to the time lag of China. Japanese loanwords source of this period are mainly three types: a Japanese transliteration or translation of Western words; Second, Japan in modern Western translation words borrowed from ancient China when Chinese vocabulary; Third, the Japanese with Chinese characters own words. Since the characteristics of the times, these three words on the source borrow mainly in political, economic and other aspects. the rapid development of the Internet, the emergence of Japanese to Chinese input on the source vocabulary of another peak. Japan's animation industry is highly developed; making the word on the source of animation into China has become the subject. They are rich in the number of Chinese vocabulary, become a new bright spot in the Chinese vocabulary.

Since the word on the source of animation through the network became popular later, not only on television, radio, newspapers and other media frequently appear, people in their daily lives are often used. Loan Words coexist with intrinsic meaning, enriching the expressive Chinese. For example, come hot word "Moe" relevant there, in November 2012, "China Daily" entertainment of a title is the "' good man "massive exposure Highlights sell Meng Song Joong-ki off screen." "Moe" comes from the Japanese anime film and television works, which means "cute" but surpasses "cute" What a little like "people pity, want to protect," the subtle emotions, this one word can express the vivid very complex a very delicate state, greatly enriched the expressiveness of Chinese. As another example, "control" is derived from the Japanese anime source, it means "extremely liked", more on a noun ending, represents something extreme like. June 2011 a headline Netease news on the "'brand control' 'spell personality' not bad money 'terrible schoolchildren high consumption", read newspapers everywhere "Royal Sister control," "Lolicon "'" Uncle control ", even particularly like cats who also call themselves" cat control. " Acceptance and use of these high-frequency words unconsciously, we can see the network popular word on the source animation on the big influence of the Chinese language.

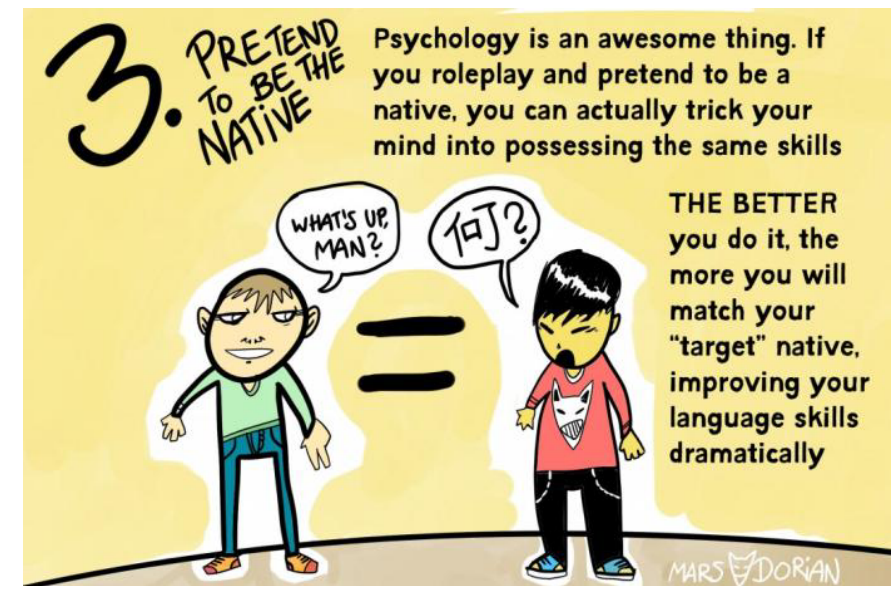

Figure 1. Japanese anime language manifestations

\section{Date source of popular anime loanwords reason}

China is still in the stage of gradually opening up, needs a substantial absorption of foreign things. Since the seventies the world, so that the country's reform and 
opening policy to gradually open, people especially ideological emancipation of young people, they tend to be more recognition of foreign cultures and admiration. Groups of young people is desire and curiosity to explore the most exuberant of a group, they curious foreign things. ACG industry is well developed in Japan, has become Japan's third-largest industry, work another, their influence has gone beyond the young audience, the whole Japanese society have caused a huge impact. Since the vocabulary as the language most active part, the impact of culture on the language of ACG is highly concerned about Japanese linguists. ACG contemporary popular culture on Chinese youth groups also have a lot of appeal. Them by creating virtual characters and virtual environments, creating the ideal audience for our country a spiritual, so ACG fans especially curious teens become their huge consumer groups. In adolescents view, the new language phenomenon using ACG works appeared, new vocabulary is a fashion and trend, is the cool thing to satisfy their vanity. In addition, because these new words can be more aptly express their living conditions and psychological mood, it led to the ACG as the background on the source term is mainly popular among the young people in our country. Based on the source network buzzwords spread the particularity, that is, the majority of the youth groups. Through investigation and analysis, we believe that the main source of the words highlighted in popular Japanese youth groups because of the following two aspects.

Affix type buzzwords of today's popular discourse is one of the largest number, whether constituting the popular word, phrase or forms of discourse constitute popular buzzwords ways it is a very Nanchang way. For example, in Japan the source buzzwords, buzzwords affixes formula derived by the word formation produced particularly prominent, but also particularly easy to people to accept. This is due to affix class affixes the original meaning of the occurrence of a class, blur, then known by different root meaning with these affixes, affixes a combination of class, and then you can get a set of words, a group represent the same class things, words. One need only know that a group of similar meaning, structure the same words in one can guess the meaning of the other, so it is very easy to be understood and accepted, once people accepted, they have a strong diffusion capacity Their relative to other words in terms of vitality will be more powerful and will adapt to the development trend of modern Chinese. We can say that the class affixes word formation is derived in large numbers of new words and the most important and most effective way, so we can predict where there will be many similar affixes, they form new words from the derivative will continue to produce.

In the three elements of language (pronunciation, vocabulary, grammar), and vocabulary system is the most open, most sensitive to social changes in living systems. The emergence of a large number of the current date to reflect new things and new concepts of source words can easily enter the Chinese; it is precisely because of the language to meet the people's psychological innovative ideas. The domestic newspapers, magazines, television, Internet media also played a major role in fuelling that in order to attract readers, the audience's attention, use a lot of new popular language, especially advertisements that they tend to use more Borrowed words, This helps popular date source word and their penetration of the Chinese vocabulary system.

Domestic scholars said: "The emergence of new words and styling follows the principle of necessity first language, followed by word-building must comply with the basic rules and methods of the Chinese language, and reflect the efficiency of communication." Through investigation and analysis, we can see Prior to reflect new things, new concepts generated daily source buzzwords, Chinese original is no word to express this new thing, or existing words can not express new concepts and new things, new concepts accurately, For example, "seiyuu, dry woman, otaku, doujinshi, character set" and other Japanese animation industry to bring new things, and the resulting words reflecting these concepts, so they can be spread popular in contemporary youth groups .

To avoid dull repetition is verbal communication, and thus be vivid. Use foreign words sometimes can better achieve this aim. For example, "disappeared" intent to suddenly disappear, only for the Japanese people and not for things, it first appeared by Imamura Lu Ping in 1967 Japanese film director's name. "Disappeared" is made out of words to use metaphors, lively and expressive. At that time the Chinese, there is no such a word, and therefore the introduction comes. There are other similar such "home -, - family, - control, - Moe, into chaos, Cannian, seiyuu, colleagues," and so on, they are new, interesting, can add a lot of fun as the language of life.

China and Japan on the geography, culture are close to, and use of Chinese characters in both countries long ago. After some characters were introduced in Japan in the past followed the ancient Chinese original meaning, but the meaning of the word in modern Chinese changes; some were they given a new meaning, has become a new word. Date source buzzwords are basically Chinese Words on the source, the Chinese people friendly, easy to understand, easy to use, easier to absorb than the foreign words in other languages. Humanities and social science aspects of vocabulary we use today have 70 percent input from Japan, these are Japanese translation of words corresponding to the West, came to China after the Chinese took root. Although 70 percent of the data needs to be further research, but at least show the influence of the large Japanese to Chinese. This phenomenon is mainly because both countries use Chinese characters, but also because of this, in the process of entering the Chinese words on the source, the borrowing glyph is the highest proportion of borrowed Kanji font that is used directly.

\section{ACG background}

With the rapid development of computer, networking and electronic technology in today's world we have entered 
the era of the ACG. This is not only reflected in the ACG booming industry itself, but also in the ACG basic necessities to people and other non-electronic industries occupation. The rapid development of the ACG make derivative products are no longer limited to text, pictures and games and other entertainment industry, but beyond the entertainment itself, throughout all aspects of daily life, such as clothing, food, stationery and so on, and in the very land of degree Vocabulary affected country. For example, the current buzzwords in the Japanese source words and animation-related proportion accounted for a large part, such as is currently popular "Lolita, is too, royal sister, natural stay, transsexuals, girl, faithful dog attack, soft sister glasses mother "they represent a class of distinctive characteristics of the avatar. In addition there are many words in the animation on the source network and everyday life are teenagers who frequent use of, this phenomenon reflects the characteristics of the times contemporary teenagers interested in animation.

Date source buzzwords in addition to most of the impact generated by the animation industry, and partly from the Japanese daily buzzwords, such as "up, Kara OK, discount, popular, old lady," and so on, as these words in society each class is used, but is not limited to youth groups. In the youth groups reflected more prominent, or buzzwords in recent years from Japanese anime.

As a new media network, with fast and instant delivery functions mass duplication of information, speed of its spread, the spread of a wide range of benefits unmatched by traditional media. Therefore, the network can best reflect the latest changes in the language and direction of development of language. Date source buzzwords on the network by means of this convenient and efficient newborn media pop up quickly. For example, ACG fans online exchanges frequently use the "sell Meng things, Meng pet" and other words, the impact of other Internet users, "Moe" was soon a popular network.

Date source buzzwords in vogue among young people by a variety of causes, partly because the Internet population is mainly young people; the other hand, youth groups or because of their own characteristics caused. In summary, we believe that second genesis mainly in the following three points: First, the closed state of adolescent life; Second, teenager's individuality and spirit of the times; Third, adolescent special cultural state of mind.

The information age has changed the way people live and work in today's way, especially contemporary teen life. It caused a lot of teenager's over-reliance on networks and electronic products, with little contact with other people and society, living in their own virtual world, avoiding the real world. For example, the words of the living conditions of the expression "otaku, house woman, otaku, dry female" and other popular teen to reveal contemporary special living conditions, "home" has become a trend. Sometimes, indeed, the virtual world than the real world seem more freedom and better, so that teenagers are more willing to stay home and soak in the network, animation, games and other virtual world, greatly reducing the chance of their exchanges and contacts with the outside world, and online communication is not face to face, but through the Internet, text messaging, voice, video, etc., such a longterm life of the particular state is bound to affect the cultural and psychological status of adolescents.

\section{Teen individuality zeitgeists}

This is a show themselves, individuality era. Especially contemporary teenagers, their pursuit of self-personality and distinctive style, outstanding performance for the following two characteristics: First, some young people challenge the traditional, self-advertised, there is an urgent need to do "non-mainstream" rebellious thoughts and find their own sense of presence psychological needs. This makes them the time to put some new buzzwords mention as their symbol, seen as one kind of distinctive way to express themselves. , Youth groups like the Japanese source buzzwords are derived from animation, online games and other virtual fields that interest them, these words are very strange virtual realm, such as "positive too, into chaos, colleagues" and look at the literal is difficult to know their meaning, it is difficult for adults to understand, which help youth groups to some extent between themselves and the adult world drew a boundary, highlighting their existence, highlighting its own unique personality; Second, some young people good fun of his own to keep up with the mainstream, but also to strive for the traditional mainstream of life is full of longing. For example, "Tucao" popular term, it reflects their spirit is good at self-deprecating, but also reflects their say, the courage to face their own shortcomings characteristics. Another example is the "blood" is the popular term embodies a "cheer, the goal of forging ahead," the mood, reflecting the kind of people they are excited, who worked hard to aspire to but more unreal life.

Network buzzwords to reflect the psychological state of contemporary youth highlighted in the following two aspects: First, the psychological refuse to grow, young technology, habitual act cute and evade social responsibility. For example, the very popular "Lolita, is too," the property is "Moe", and this "Moe" word generated from the time since it was labeled "play cute" label. Earlier, "Lolita, is too" cute girl is about 9-14 years old, boy, over time, gradually expanded the meaning to be used to refer to psychological naive, looks cute young twenties, so "sell Moe" has become a ages and gender "play cute" behavior. This fully demonstrates the contemporary teenagers generally have refused to grow up attitude; Second, aesthetic diversity, gender perspectives blur. Be able to demonstrate this feature contemporary adolescents have the word on the source animation, such as "transsexuals, slash, rot, attack by, BL (Boys 'Love), GL (Girls' Love)". The "pseudo-mother" means the same good looks, tall and weak, are often mistaken for girls males. The term "pseudo-mother" does not necessarily imply that men are the same as the traditional aesthetic concepts to be tall, powerful, strong and have to play. ACG and many works are "pseudo- 
mother" image, and today's real life there have been many feminine men, they can confidently beauty, makeup, dress, become the representative of "the influx of people, range of children", gradually It also accepted the existence of such an image. In addition, like "slash, rot, attack by, royal sister" and other words also subvert the traditional concept of understanding in men, women and intercourse between status modes.

\section{Standardization of network buzzwords}

People enjoy the convenience of a modern and efficient network of life, but also bound to pursue the modernization of the network language. Modernization will bring endless stream of fresh vocabulary, if these terms are not regulated and properly guide will cause confusion network language. Therefore, standardized network language is multifaceted system engineering, in addition to Internet-related institutions management personnel, language, educators, especially media workers, which are entrusted with a very important responsibility.

Ideal network language life should be like this: not only colourful, but also methodical; both can well reflect the era of style, but also rational tradition; both accepted by the community, it also enabled the network to obtain pure language itself maintain. Even the language of selfregulation can work, but in order to faster and better achieve this goal, we need to correct social network language intervention. How to intervene is intervene in what areas, this has yet to be linguists to further research and discussion. In addition to the efforts of professionals, each Internet users on the network language specification also has an inescapable responsibility, should consciously regulate their own network terms. The pursuit of modern life makes people have in their daily lives at the expense of Chinese learning opportunities for the price. Due to increased foreign language, computer and other courses keeping with the times, our primary and secondary schools now time for language education less and less. And the method of language teaching seems there are a lot of problems. Therefore, the whole society should rerecognize the importance of language learning, renewed interest in and importance of language learning and education, the only way to promote the improvement of the quality of national languages, in order to make a real standardization network language be achieved.

The fastest network buzzwords reflect social life of the state language phenomenon closely integrated with the times. We should adopt a dialectical perspective to view the new era of Chinese network buzzwords. We should fully recognize that a new era of Chinese Internet buzzwords in the vast majority can remain worthy of praise because they are in modern society the collective wisdom of the people. Chinese network buzzwords leading the trend of Chinese vocabulary development, reflecting the trend of the future development of Chinese vocabulary. It enables the modern Chinese language more lively, more modern at the same time, also continue to integrate into the Chinese vocabulary, rich and expanding the vocabulary of modern Chinese family. Of course, we must also see many shortcomings that exist in the network buzzwords. For example, many expressions unreasonable, non-standard or even unhealthy; many buzzwords, there are some vague concept, ideographic unclear, to cause trouble understanding our language, so the phenomenon burden. After all, only a minor aspect of the lack of contradiction, we can not deny the main aspects of conflict. So we can not because of lack of network buzzwords and negated network buzzwords. Only to see the shortcomings of the kind of network is considered buzzwords network buzzwords "unrefined", there is no research value of speech is one-sided and unscientific, but also we have to be abandoned. We should dialectical view network buzzwords that only a comprehensive and objective understanding of the network buzzwords can truly guide scientific and standardized network buzzwords.

\section{References}

1. Chen Dandan, Chen Lin. Students analyze "otaku house female" phenomenon of Neijiang Normal University, 12 (2010)

2. Peng Yubo. Some Features of Network Language. Rhetorical study, 4 (2001)

3. Lin Gang. Types and characteristics of the network terminology. Rhetorical study, 26 (2002)

4. $\mathrm{Li} \mathrm{Li}$. The nature and characteristics of the network words. Language Studies, 21 (2005)

5. Cao Guojun Comics - Animation - Cartoon • animation. Language knowledge, 7 (2006)

6. Chu animation as a language in contemporary cinema, 3 (2010)

7. Feng. Foreign Language Teaching hear the application of multimedia teaching methods. Chinese education technology and equipment, 20, (2008)

8. Gu Jiangping. Analysis of contemporary Japanese Loan Words on Chinese penetration. Kanji culture, 1 (2000)

9. Luo Yixian, party Wei Ying. On the influence of Japanese animation culture of our young people. Science garden, 6 (2008)

10. TURAL multimedia technology on Foreign Language Listening Course of Modern Languages (late), 05 (2006) 